\title{
Behavioral Interactions between a Native and an Invasive Fish Species in a Thermally Heterogeneous Experimental Chamber
}

\author{
Lindsy R. Ciepiela ${ }^{1,2}$, Ryan M. Fitzpatrick ${ }^{1,3, * \mathbb{D}}$, Samuel T. Lewis ${ }^{3}$ and Yoichiro Kanno ${ }^{3,4}$ \\ 1 Colorado Parks and Wildlife, Research, Policy, and Planning Section, 317 West Prospect Rd., \\ Fort Collins, CO 80526, USA; lrciepie@gmail.com \\ 2 Oregon Department of Fish and Wildlife, 305 North Canyon Blvd., Canyon City, OR 97820, USA \\ 3 Department of Fish, Wildlife, and Conservation Biology, Colorado State University, 1474 Campus Delivery, \\ Fort Collins, CO 80523, USA; samuel.lewis@colostate.edu (S.T.L.); yoichiro.kanno@colostate.edu (Y.K.) \\ 4 Graduate Degree Program in Ecology, Colorado State University, 1474 Campus Delivery, \\ Fort Collins, CO 80523, USA \\ * Correspondence: ryan.fitzpatrick@state.co.us; Tel.: +1-970-472-4336
}

Citation: Ciepiela, L.R.; Fitzpatrick, R.M.; Lewis, S.T.; Kanno, Y. Behavioral Interactions between a Native and an Invasive Fish Species in a Thermally Heterogeneous Experimental Chamber. Fishes 2021, 6, 75. https://doi.org/10.3390/ fishes 6040075

Academic Editor: Rafael Miranda

Received: 19 October 2021

Accepted: 1 December 2021

Published: 7 December 2021

Publisher's Note: MDPI stays neutral with regard to jurisdictional claims in published maps and institutional affiliations.

Copyright: () 2021 by the authors. Licensee MDPI, Basel, Switzerland. This article is an open access article distributed under the terms and conditions of the Creative Commons Attribution (CC BY) license (https:// creativecommons.org/licenses/by/ $4.0 /)$.
Abstract: Mechanisms of the displacement of native fish by nonnative fish can include agonistic behaviors that push native fish species out of their preferred habitat, including their thermal optima. To examine these interactions, we built an experimental thermal preference chamber to evaluate: (1) the thermal preference of native, glacial relict northern redbelly dace Chrosomus eos; (2) if the thermal preference and movement changed in the presence of the invasive western mosquitofish Gambusia affinis; and (3) the direction of agonistic interactions. We hypothesized that G. affinis would express agonistic behavior toward C. eos, because G. affinis is widely recognized as an aggressive invader. Given the temperature range of the experimental chamber, i.e., $20-30^{\circ} \mathrm{C}, \mathrm{C}$. eos selected an average of $24.3^{\circ} \mathrm{C}$ as its thermal preference. After G. affinis' introduction, the thermal preference of C. eos increased by $1.7^{\circ} \mathrm{C}$ and the movement, given by distance $(\mathrm{cm})$ travelled, increased by $21 \%$. Contrary to our prediction, more agonistic interactions were observed in C. eos toward G. affinis. These results indicate that agonistic behavior of G. affinis toward native fish species may be species- and condition-specific, and may not always be the primary mechanism of native species' displacement. Biological invasions are a global issue and altered thermal regimes are expected to continue. This study provided the novel approach using of a thermally heterogeneous thermal chamber to examine thermal preferences and aggressive interactions between a native and an invasive species. Future research should examine other life history traits that may be conveying the competitive advantage to G. affinis.

Keywords: agonistic behavior; thermal preference; condition-specific competition; Chrosomus eos; interspecific competition; Gambusia affinis; northern redbelly dace; western mosquitofish

\section{Introduction}

Nonnative fish are implicated in the demise of native fish globally, but a mechanistic understanding of how displacements take place is often lacking [1-3]. Mechanisms of displacement may include agonistic interactions, where aggressive behaviors by nonnative species push native species out of their preferred habitat, including their thermal optima [4-6]. Western mosquitofish Gambusia affinis (Baird \& Girard, 1853) is listed as one of the 100 worst invasive species by the International Union for Conservation of Nature and has been implicated in the decline of freshwater fish [7-9], amphibians [10,11], and invertebrates [12-14]. A suite of ecological traits confer competitive advantages to G. affinis, including broad physiological tolerances (i.e., eurythermic) and high fecundity $[15,16]$, but their aggressive behaviors are considered a key mechanism in native fish's displacement [17-19]. These agonistic interactions can result in an increased movement, which 
is an energetic cost that can require fish to consume more food [20], increase predation risk [21], and reduce growth [22].

The northern redbelly dace Chrosomus eos Cope, $1861=$ Phoxinus eos (Cope, 1861) is declining on the western edge of its distribution, where it is a glacial relict species. Although the species is stable throughout much of its range and has an IUCN status of "least concern", it is listed as "endangered" in Colorado, and "threatened" in Nebraska and South Dakota [23]. Threats to C. eos include alterations to its habitat and the presence of invasive species [23]. C. eos prefers off-channel lentic habitats, and has a strong preference for spring-fed habitats that are densely vegetated, such as beaver ponds [24,25]. In occupied habitats $>0.3 \mathrm{~m}$ deep, Bestgen [24] observed a strong thermal stratification, with surface to bottom temperatures ranging from 27 to $18^{\circ} \mathrm{C}$, respectively. Likewise, $G$. affinis uses the same habitat and has an overlapping thermal range with C. eos. G. affinis tolerates temperatures up to $39.5^{\circ} \mathrm{C}$ [26] and has a preferred temperature, under laboratory conditions, of $31^{\circ} \mathrm{C}$ [27]. Because C. eos occupies a thermally stratified habitat, its localized displacement by G. affinis may result a thermal displacement.

Temperature regulates the physiological and metabolic processes of ectothermic fish and is considered the abiotic ecological master factor $[28,29]$. As such, temperature influences growth [30], development [31], and behavior [32]. In habitats with micro-spatial thermal variation, ectotherms behaviorally thermo-regulate, fine-tuning trade-offs between thermal and competing resources (i.e., food) to optimize physiological and metabolic processes-ultimately maximizing the fish's fitness [33-35]. The thermal displacement of a native species by a non-native species has the potential to interrupt the former's thermal regulation, therefore interrupting the optimization of its physiological and metabolic processes. Instances where the inter-specific competitive dominance changes as a result of the environment (i.e., temperature) are known as condition-specific competition [36-39].

Studies have investigated temperature condition-specific competition by examining swimming performance among salmonids [38] and aggressive interactions of G. affinis [39]. While the foraging success and aggression of G. affinis increased significantly at higher temperatures, these fish were subject to thermally constant tanks at only three experimental temperatures [39]. Our current study aimed to examine behavioral interactions between native and nonnative species in a thermally heterogeneous setting simulating a thermally stratified micro-habitat, such as off-channel pools or beaver dams [40]. We observed fish's aggression to test for the presence of inter-specific competition and the frequency of C. eos' displacement to a non-preferred habitat. Aggressive behaviors in fish are influenced by a variety of factors including their size, societal status, prior residency, and temperature [41-43]. Elucidating how strongly thermal conditions mediate inter-specific competition is critical for predicting the population persistence of native species, especially for species with a relatively narrow thermal tolerance such as glacial relict species [44].

To inform conservation actions, we hypothesized that the displacement from preferred thermal range occurs due to agonistic behavior of G. affinis toward C. eos. Trials were conducted in a thermal preference chamber to determine: (1) the thermal preference of $C$. eos, (2) if the thermal preference changed with the addition of the invasive G. affinis, and (3) the direction of agonistic interactions.

\section{Materials and Methods}

\subsection{Ethics Statement}

The care and use of experimental animals complied with the State of Colorado's animal welfare laws, guidelines, and policies as approved by the State of Colorado Scientific Collection License \#05-AQ963.

\subsection{Experimental Fish}

Adult C. eos (average total length $\left(\mathrm{L}_{\mathrm{T}}\right) \pm \mathrm{SD}=40 \pm 4 \mathrm{~mm}$ ) were obtained from the Colorado Parks and Wildlife John W. Mumma Native Aquatic Species Restoration Facility in Alamosa, CO, USA. Adult G. affinis $(31 \pm 4 \mathrm{~mm})$ were captured using a two-person 
pull seine from the South Platte River, near Greeley, CO, USA. C. eos and G. affinis were held in ten five-gallon holding tanks at the Colorado Parks and Wildlife Aquatic Research laboratory in Fort Collins, CO, USA. The stocking density of C. eos and G. affinis was 18-20 and 10-12 fish/tank, respectively. Holding tanks were separated by visual barriers, and supplied with on-site well water, aerated, and heated to $25^{\circ} \mathrm{C}\left( \pm 1^{\circ} \mathrm{C}\right)$ using submersible aquarium heaters. Fish's health and holding tank temperatures were monitored daily. Test fish were held in holding tanks for at least 21 days prior to testing, and were fed ad libitum rations of Tetramin tropical flakes two times per day. Additional feeding of Tubifex spp. occurred once per day. Fish were fasted 12-14 h prior to the initiation of the experiment and were not fed during testing to limit the influence of their digestion on their temperature selection.

\subsection{Experimental Apparatus}

We used a modified Myrick-type thermal preference chamber to quantify the thermal and behavioral response of C. eos to the introduction of G. affinis (Figure 1) [45]. We made several modifications to the original thermal preference chamber design as described by Myrick et al. [45]. Most notably, we decreased the number of constant-headwater distribution reservoirs from four to two and eliminated the distribution lines that carried the source water directly to the mixing chamber. Water was instead piped from a warm $\left(31 \pm 0.2^{\circ} \mathrm{C}\right)$ and a cool $\left(19 \pm 0.2^{\circ} \mathrm{C}\right)$ constant-headwater distribution reservoir into two stacked mixing rings located above the chamber. The top mixing ring was a complete circle and supplied water for diluting the temperature of the bottom mixing ring. The bottom mixing ring was nearly a complete circle but, unlike the top mixing ring, was capped at both ends. Water from the top mixing ring was funneled into the bottom mixing ring at 20 evenly spaced locations, effectively diluting the concentration of the bottom mixing ring's source water along the ring. The highest concretion of the bottom mixing ring's source water was located at the center point between the two capped ends and decreased as it radiated out from the center point toward each capped end (Figure 1). The dilution of the bottom ring from the top ring created a $10{ }^{\circ} \mathrm{C}$ circular thermal gradient $(21.2 \pm 0.71$ to $29.4 \pm 0.59^{\circ} \mathrm{C}$ ). Switching between cool and warm water delivered to the top mixing ring reversed the orientation of the thermal gradient and allowed us to randomize the thermal gradient orientation during trials. When cool water was delivered to the top mixing ring, the water temperature decreased from $30^{\circ} \mathrm{C}$ to $19^{\circ} \mathrm{C}$ as it traveled from the center point to the two capped ends. The gradient was reversed when warm water was delivered to the top mixing ring.

Water from the bottom mixing ring was funneled into the 20 sections (increased from 8 in the original Myrick-type [45] thermal preference chamber) of the mixing chamber. Water flowed from the mixing chamber into the swimming chamber through 60 evenly spaced holes (3 per section). The swimming chamber's outer wall had a diameter of $101 \mathrm{~cm}$, and the inner wall was $80 \mathrm{~cm}$. Water then flowed through 32 evenly spaced holes, into the 32 sections (increased from 8 ) of the effluent channel before finally flowing through 32 holes ( 1 per section) to three drains located in the base of the chamber. The apparatus created a continuous $10^{\circ} \mathrm{C}$ circular thermal gradient (mean segment temperature $\pm 95 \%$ CI; $21.2 \pm 0.7$ to $29.4 \pm 0.6^{\circ} \mathrm{C}$ ) with the capacity to control flow direction (Figure 2). We randomized the thermal gradient orientation between trials to ascertain whether fish were selecting a temperature and not a location in the chamber (Figure 2). The thermal chamber was enclosed with a curtain, and a $122 \mathrm{~cm} \times 122 \mathrm{~cm}$ sheet of white Plexiglas was mounted above the chamber to eliminate external disturbances during trials and allow for a uniform lighting of the chamber. 


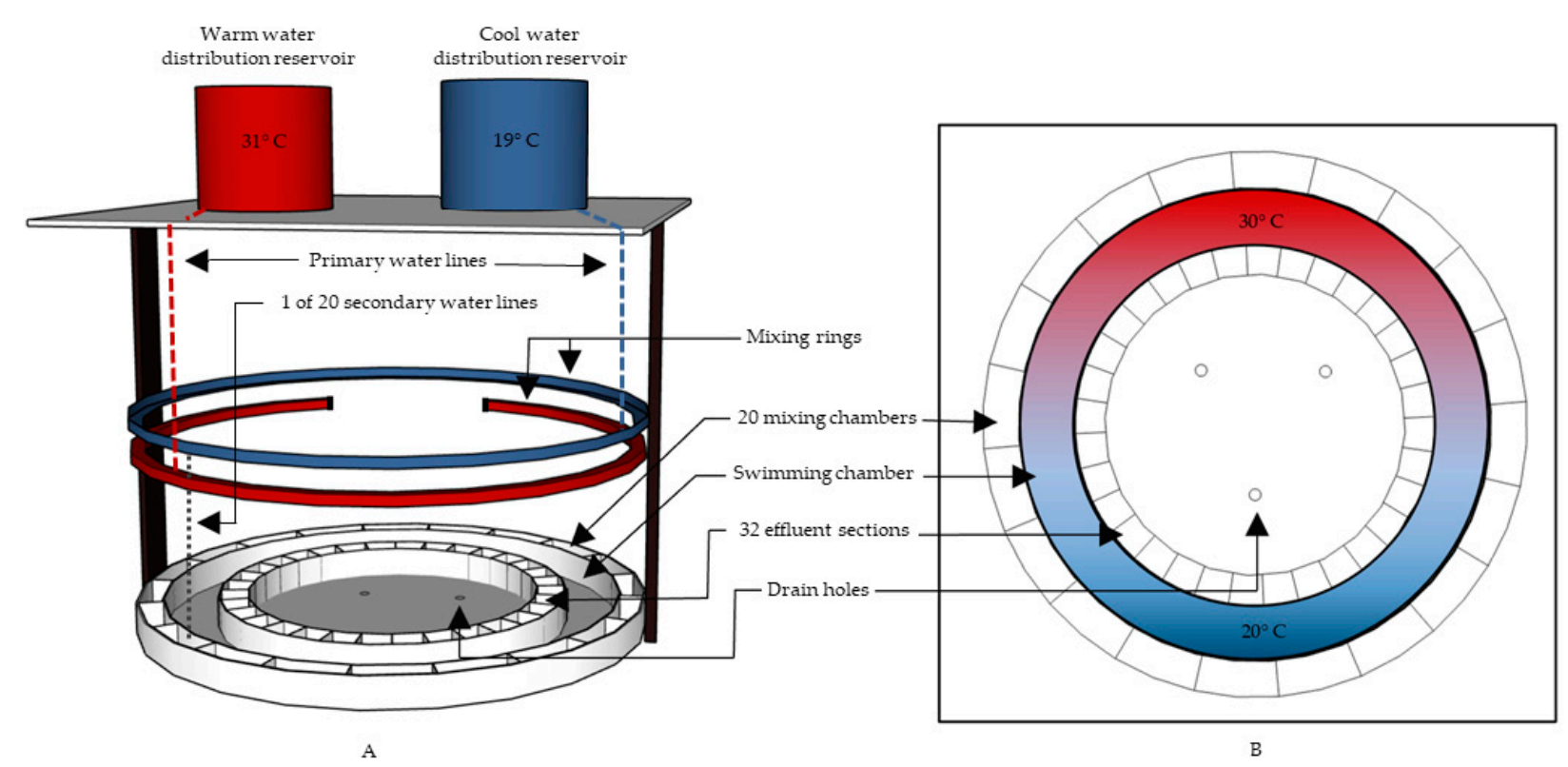

Figure 1. Lateral (A) and overhead (B) views of the thermal preference chamber that was used to quantify fish's thermal preference and movement (modified from Myrick et al. [45]). One of the 20 secondary water lines is shown to provide an example of the water distribution from the top mixing ring to the bottom mixing ring and finally into the mixing chamber. The remaining 19 secondary water lines were equally spaced around the mixing rings, with their location corresponding to the center of each mixing section.

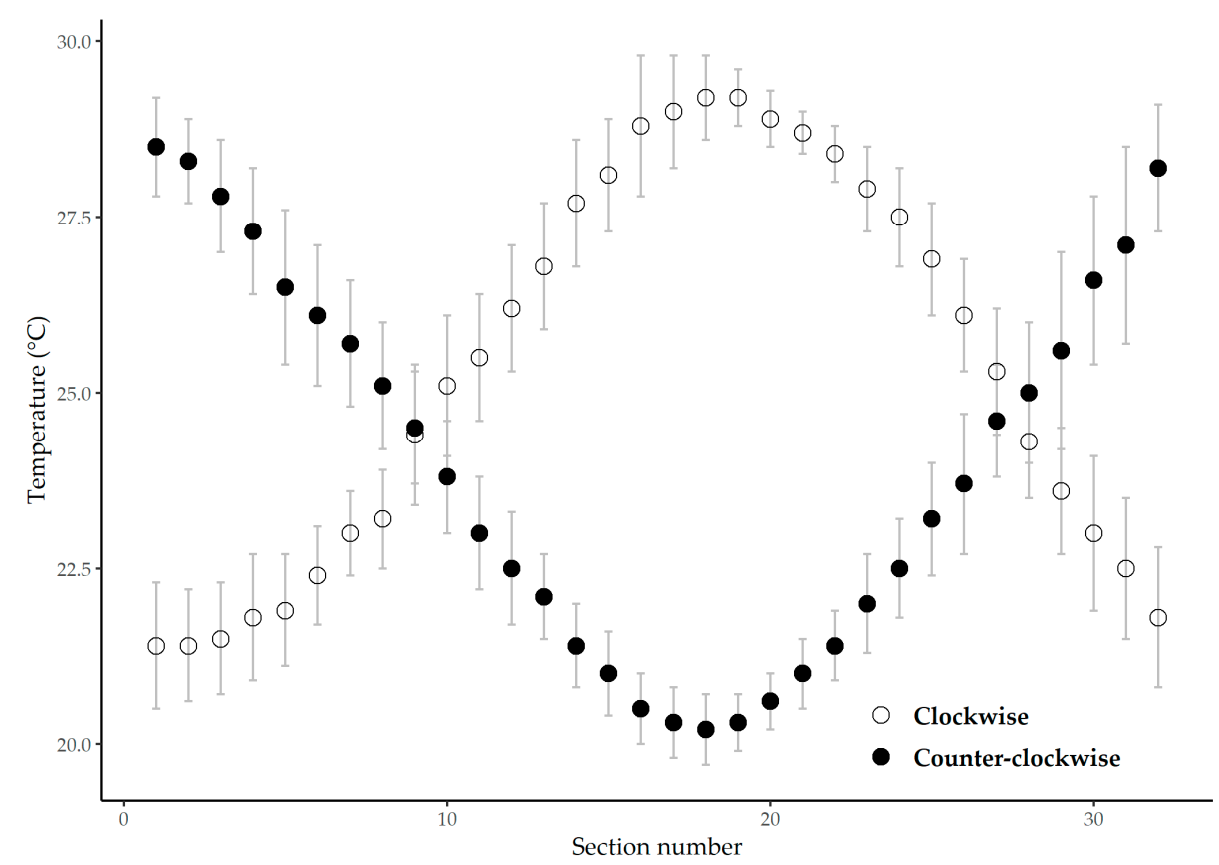

Figure 2. Mean ( \pm standard deviation) water temperature recorded immediately prior to initiating trials assigned to one of two flow directions, clockwise (open circles) or counter-clockwise (closed circles). The water temperature was measured in the swimming chamber at the center of 32 equidistant visual sections.

\subsection{Experimental Fish Trials}

We first estimated C. eos' thermal preference, and then proceeded to add G. affinis (i.e., the treatment) to quantify the thermal and behavioral response of $C$. eos to the introduction of G. affinis. A total of 11 trials were completed, and each trial consisted of two 60 min runs. Run 1 represented the reference condition period and was used to establish the thermal 
preference and travel distance of an individual C. eos. After a $15 \mathrm{~min}$ acclimation period, Run 2 began, representing the treatment period, which was used to observe changes in $C$. eos' thermal preference and travel distance due to the introduction of three G. affinis.

Prior to each trial, we randomly selected a thermal gradient orientation (clockwise or counter-clockwise) and allowed the preference chamber to equilibrate for $30 \mathrm{~min}$. We then measured the thermal gradient of the annular chamber at 32 equally distanced locations (Figure 2). At the initiation of each trial, we removed one C. eos from its holding tank and introduced it into the thermal chamber at the location corresponding to the fish's acclimation temperature of $25^{\circ} \mathrm{C}$. Test fish were randomly selected and measured for $L_{T}$ prior to their introduction into the thermal chamber. After a $1.5 \mathrm{~h}$ acclimation period, we began the reference condition period of the trial, which included only the single C. eos. The results of this hour in the thermal chamber established the thermal preference of $C$. eos. Following the reference condition period, we randomly selected and introduced three G. affinis, bringing the total number of fish in the chamber to four. The G. affinis were introduced to the chamber at the same location as the initial C. eos.

During trials we video-recorded fish's movement and behavior with four web-cameras mounted $1.5 \mathrm{~m}$ above the surface of the water (Figure 3). Collectively, the four cameras were positioned to capture the entirety of the swimming chamber (Figure 3). Post-trial we used the video files to note the location, and thus temperature, of all fish at the start of every minute during reference condition and treatment periods, for a total of 60 temperatures for each fish. We noted fish's location (nose position) in relation to the 32 effluent sections. To estimate C. eos' movement travel, we visually tracked and recorded the number of sections each C. eos travelled through in the first $10 \mathrm{~s}$ of each minute during the reference condition and treatment periods and multiplied the number of sections traveled by the center width of each section $(9.6 \mathrm{~cm})$. Finally, to quantify the species interactions we counted the number of chases that occurred during the first $10 \mathrm{~s}$ of each minute in the treatment period.
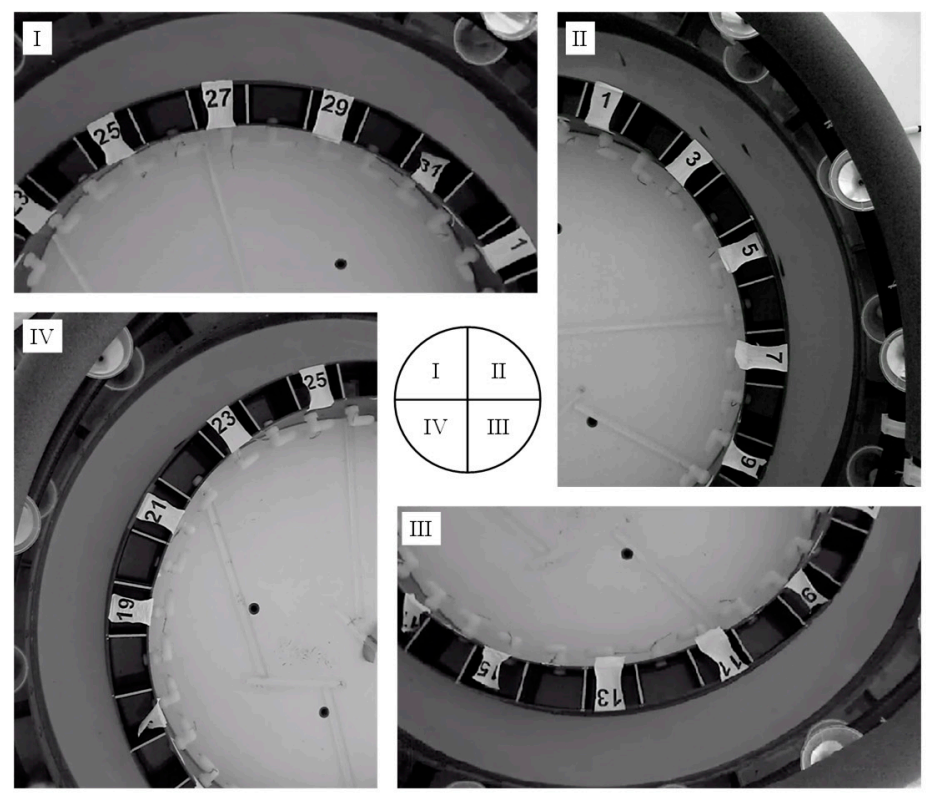

A

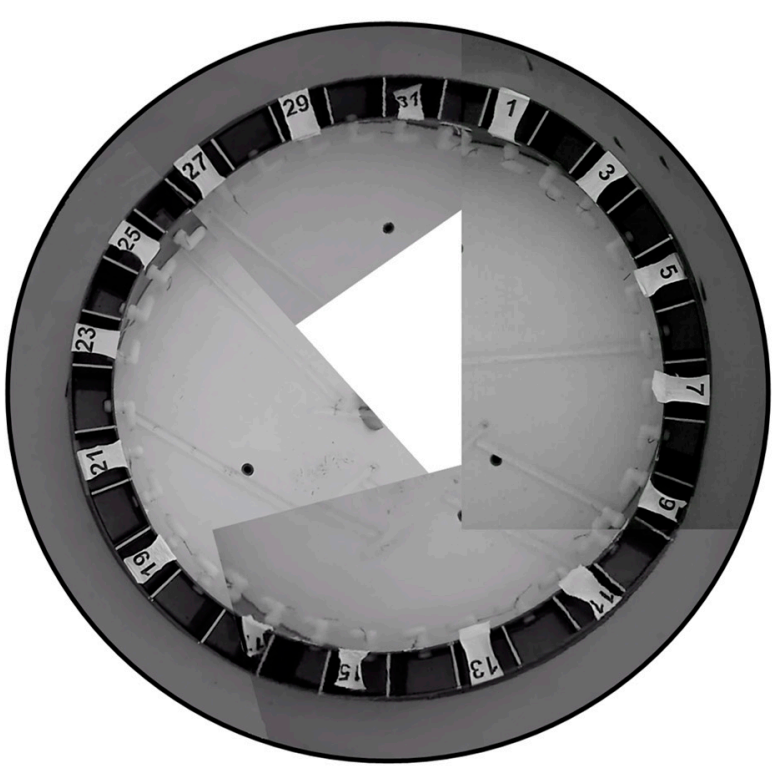

B

Figure 3. Photographs of the thermal preference chamber. (A) Display of the four camera angles. (B) Display of when the four images are merged into one. Note: There are four fish in Figure A (II) and in the upper right corner of Figure B.

\subsection{Statistical Methods}

We tested whether the temperature selected and distance moved by the C. eos, differed pre-treatment and after three G. affinis individuals were introduced into the chamber using hierarchical linear models. The response variable was the mean water temperature across sections that the single $C$. eos individual occupied, or the number of sections that the $C$. 
eos individual travelled through during a $10 \mathrm{~s}$ period at the beginning of each minute for $60 \mathrm{~min}$. The binary explanatory variable, $x_{i}$, was the presence of $G$. affinis $(0=$ pre- $G$. affinis' introduction, 1 = post-treatment). Because the temperature was continuous and the movement was discrete data, the temperature was modeled to follow a normal distribution, and the movement followed a Poisson distribution. Given a vector of temperature $\left(\right.$ temp $\left.p_{i}\right)$ and movement $\left(\right.$ move $\left._{i}\right)$ data across minutes and trials, the models are written:

$$
\begin{gathered}
\text { temp }_{i} \sim \operatorname{Normal}\left(\alpha_{\text {.temp }}[i]+\beta . \text { temp }_{j[i]} x_{i}, \sigma_{y}^{2}\right) \\
\text { move }_{i} \sim \operatorname{Poisson}\left(\lambda_{i}\right) \\
\log \left(\lambda_{i}\right)=\alpha_{\text {. } \text { move }_{j[i]}+\beta . \text { move }_{j[i]} x_{i}}
\end{gathered}
$$

We let the intercepts $\left(\alpha . t e m p_{j}\right.$ and $\alpha$. move $\left._{j}\right)$ and slopes $\left(\beta . t e m p_{j}\right.$ and $\left.\beta . m o v e_{j}\right)$ vary by trial $j$ to which observation $i$ belong, and $\sigma_{y}$ refers to the residual term (i.e., standard deviation). That is, we considered that the initial temperature selection or travel distance by C. eos, and its shifts after G. affinis' introduction, could differ among trials. To model intertrial variation and synthesize the overall pattern across trials, we modeled the intercepts and slopes as random effects, where $\mu_{\alpha . t e m p}$ is the mean overall temperature selected, and $\mu_{\alpha \text {.move }}$ is the total number of sections moved by a C. eos across $10 \mathrm{~s}$ periods prior to $G$. affinis' introduction with standard deviations equaling to $\sigma_{\alpha . t e m p}$ and $\sigma_{\alpha \text {.move }}$ (Equation (4)). Similarly, $\mu_{\beta . t e m p}$ is the mean overall change in temperature selection, and $\mu_{\beta . m o v e}$ is the mean overall change in the number of sections traveled due to the presence of $G$. affinis with standard deviations equaling to $\sigma_{\beta . t e m p}$ and $\sigma_{\beta \text {.move }}$ :

$$
\begin{aligned}
& \alpha . t e m p_{j} \sim \operatorname{Normal}\left(\mu_{\alpha . t e m p}, \sigma_{\alpha . t e m p}^{2}\right) ; \alpha . \text { move }_{j} \sim \operatorname{Normal}\left(\mu_{\alpha . m o v e}, \sigma_{\alpha . m o v e}^{2}\right) \\
& \operatorname{\beta .temp}_{j} \sim \operatorname{Normal}\left(\mu_{\beta . t e m p}, \sigma_{\beta . t e m p}^{2}\right) ; \text { B.move }_{j} \sim \operatorname{Normal}\left(\mu_{\beta . m o v e}, \sigma_{\beta . m o v e}^{2}\right)
\end{aligned}
$$

We additionally fit a model that evaluated whether inter-trial variation in intercepts and slopes could be explained by variation in the body length of $C$. eos between trials, because agonistic inter-specific interactions depend frequently on the body lengths of fish [46-48]. Specifically, we fitted linear models on intercepts $\left(\alpha . t e m p_{j}\right.$ and $\left.\alpha . m o v e_{j}\right)$ and slopes $\left(\beta\right.$.temp $p_{j}$ and $\beta$. move $_{j}$ ), where $\mu_{j}$ is the mean-standardized body length of C. eos (total length in $\mathrm{mm}$ ) used in trial $j$ :

$$
\begin{aligned}
& \alpha . \text { temp } p_{j} \sim \operatorname{Normal}\left(\gamma_{0} . \text { temp }+\gamma_{1} . \text { temp } * \mu_{j}, \sigma_{\alpha . t e m p}^{2}\right) \\
& \alpha . \text { move }_{j} \sim \operatorname{Normal}\left(\gamma_{0} . \text { move }+\gamma_{1} \text {.move } * \mu_{j}, \sigma_{\alpha . \text { move }}^{2}\right) \\
& \text { B.temp }_{j} \sim \operatorname{Normal}\left(\delta_{0} . \text { tem } p+\delta_{1} . \text { temp } * \mu_{j}, \sigma_{\beta . t e m p}^{2}\right) \\
& \beta . \text { move }_{j} \sim \operatorname{Normal}\left(\delta_{0} . \text { move }+\delta_{1} . \text { move } * \mu_{j}, \sigma_{\beta . m o v e}^{2}\right)
\end{aligned}
$$

C. eos body length did not affect temperature selection or movement; therefore, we primarily report results based on the model described above (Equations (1)-(5)).

Models were analyzed with a Bayesian approach using a Markov chain Monte Carlo (MCMC) method in the program JAGS [49] called from the program R [50] with the jagsUI package [51]. Uninformative priors were used for all parameters. Posterior distributions of parameters were estimated by taking every fifth sample from 10,000 iterations of three chains after a burn-in period of 2000 iterations. The model convergence was checked by visually examining plots of the MCMC chains for good mixture as well as ensuring that the R-hat statistic was less than 1.1 for all model parameters [52]. We considered effects of explanatory covariates (i.e., G. affinis introductions and C. eos body size) statistically significant when $>95 \%$ of posterior samples were either positive or negative; we report the proportion of posterior samples (PPS) that were in the same direction (positive or negative) as the posterior mean value. This metric ranged from 0.5 to 1 . If covariate effects are zero, 
$50 \%$ of posterior samples are approximately positive or negative; if effects are unequivocal (i.e., posterior samples do not overlap zero), $100 \%$ of posteriors samples may be positive or negative.

\section{Results}

\subsection{Thermal Preference}

Prior to G. affinis introductions, C. eos occupied an average temperature of $24.3^{\circ} \mathrm{C}$ $\left(\mu_{\alpha . t e m p}\right)$ that varied between trials $\left(\sigma_{\alpha . t e m p}\right.$ : mean $\left.=2.5^{\circ} \mathrm{C}\right)$. After $\mathrm{G}$. affinis were introduced, C. eos selected significantly (PPS $=0.98$ ) higher temperature ranges (mean $=1.7^{\circ} \mathrm{C}$ higher $\left(\mu_{\beta . t e m p}\right)$; Figure 4$)$. The magnitude of changes in temperature selection varied by trial, ranging from $-1.3^{\circ} \mathrm{C}$ to $4.7^{\circ} \mathrm{C}$.

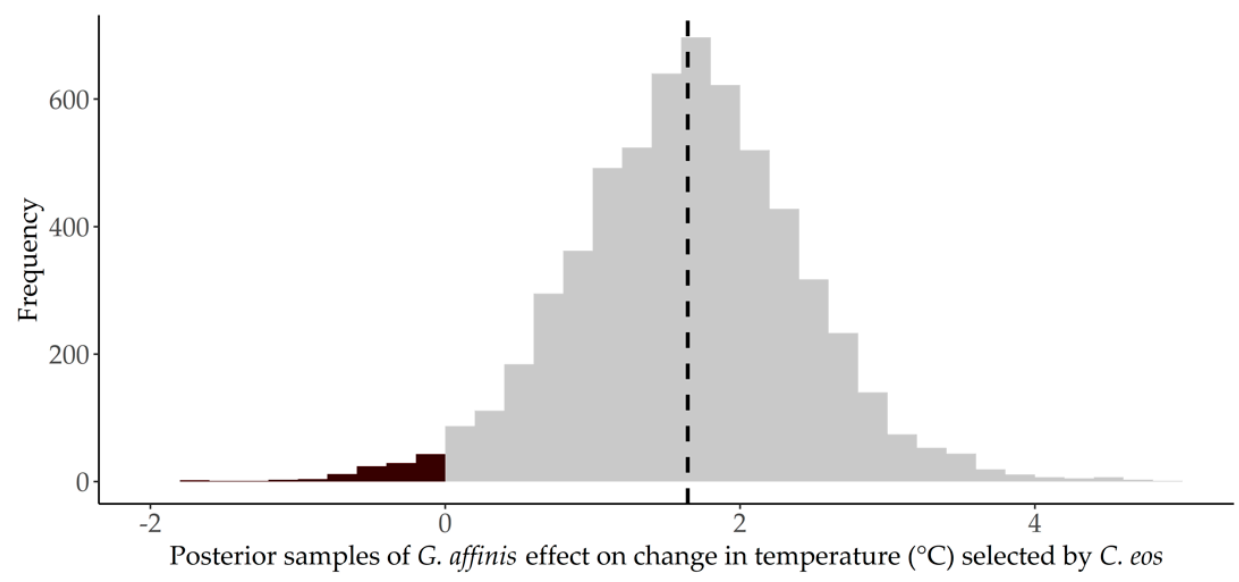

Figure 4. Proportion of posterior samples (PPS) of Gambusia affinis introduction effects on the change in temperature selected $\left(\mu_{\beta . t e m p}\right)$ in $\beta . t e m p_{j} \sim \operatorname{Normal}\left(\mu_{\beta . t e m p}, \sigma_{\beta . t e m p}^{2}\right)$ by Chrosomus eos. Posterior samples that are positive are shown in gray and those that are negative are shown in black. The vertical black dotted line shows the mean posterior value.

The body length of C. eos did not explain the inter-trial variation in its temperature selection $\left(\gamma_{1}\right.$. temp : mean $=-0.38$, PPS $\left.=0.69\right)$ or movement distance $\left(\gamma_{1}\right.$. move: mean $=0.70$, PPS $=0.63)$ before G. affinis' introduction, or changes in its temperature selection $\left(\delta_{1}\right.$.temp: mean $=-0.09$, PPS $=0.53)$ or movement $\left(\delta_{1}\right.$. move: mean $=0.07$, PPS $\left.=0.56\right)$ in response to G. affinis introduction.

\subsection{Movement}

C. eos' movement distance increased $21 \%$ after G. affinis were introduced. Without $G$. affinis, C. eos moved an average of 10 sections $(96 \mathrm{~cm})$ per $10 \mathrm{~s}$ across minutes and trials. After G. affinis introductions, C. eos moved an average of 12 sections $(116 \mathrm{~cm})$, and this effect was statistically significant $\left(\mu_{\beta . m o v e}\right.$ : mean $=0.36$ ( $\log$ scale), PPS $\left.=0.96\right)$ (Figure 5$)$. Again, the change in the movement distance of $C$. eos varied by trial, ranging from two fewer sections moved to nine more sections of movement after G. affinis' introduction. 


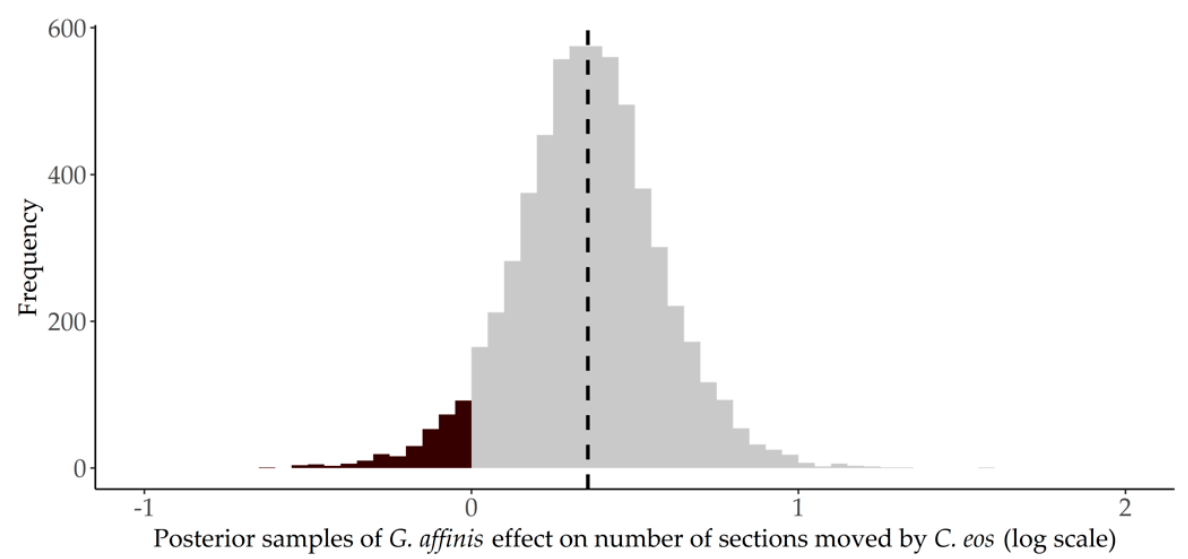

Figure 5. Proportion of posterior samples (PPS) of Gambusia affinis' introduction effects on the distance moved $\left(\mu_{\beta \text {.move }}\right)$ in $\beta$. move $_{j} \sim$ Normal $\left(\mu_{\beta \text {.move, }} \sigma_{\beta \text {.move }}^{2}\right)$ by Chrosomus eos. Posterior samples that are positive are shown in gray and those that are negative are shown in black. The vertical black dotted line shows the mean posterior value.

\subsection{Agonistic Interactions}

Contrary to our prediction, more agonistic interactions were initiated by C. eos toward G. affinis than the opposite. We recorded interspecific interactions (i.e., chases) in 2562 out of 6600 total seconds of observations (39\%). Of these, 1976 observations $(77 \%)$ were chases by C. eos of G. affinis, and 348 observations (14\%) were chases by G. affinis of C. eos (Figure 6). In the remaining 238 observations (9\%), G. affinis and C. eos chased each other, and we could not determine which species initiated the interactions.

C. eos toward G. affinis

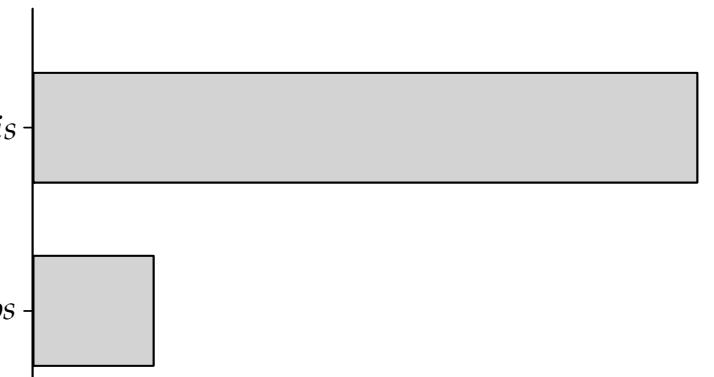

Not determined
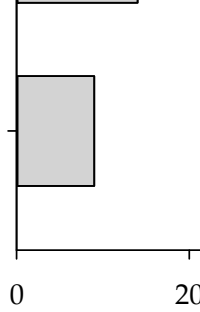

20

40

60

80 100

Percent of chases

Figure 6. Direction of agonistic interactions between C. eos and G. affinis.

\section{Discussion}

Our results indicated a temperature preference of $C \cdot \cos \left(24.3^{\circ} \mathrm{C}\right)$ slightly lower than the temperature preference of $25.3^{\circ} \mathrm{C}$ estimated by Stauffer et al. [53] when integrating temperature preferences of fish acclimated to five different temperatures $(6,18,24,30$, and $33{ }^{\circ} \mathrm{C}$ ). However, the preferred temperature of $24{ }^{\circ} \mathrm{C}$-acclimated C. eos reported by Stauffer et al. [53] $\left(24.0^{\circ} \mathrm{C}\right)$ was similar to the preferred temperature of the $25^{\circ} \mathrm{C}$-acclimated C. eos in this study $\left(24.3^{\circ} \mathrm{C}\right)$. The similarity in the preferred temperatures between these two studies was interesting given the differences between the C. eos source populations used in each study. The source population of the hatchery-propagated C. eos used in this study was West Plum Creek (a tributary to the South Platte River, CO, USA), which is 
at approximately 2,000 $\mathrm{m}$ in elevation, whereas the source population of $C$. eos used by Stauffer et al. [53] was Spratt Creek (a tributary of the Thunder Bay system, Lake Huron, Michigan, USA), which is at an approximate elevation of $220 \mathrm{~m}$. As a glacial relict species in Colorado, C. eos may have experienced cooler temperatures than other populations in $C$. $e o s^{\prime}$ native range, however our results indicate that $C$. $e^{\prime} s^{\prime}$ preferred temperature remains stable across geographic regions when acclimated to similar temperatures.

The introduction of G. affinis into the thermal preference chamber increased C. eos' movement, given by distance $(\mathrm{cm})$ traveled, by $21 \%$. The increase in movement resulted in more time spent outside of C. eos' initially established thermal preference, as documented by an overall increase in the thermal selection of $1.7^{\circ} \mathrm{C}$, post G. affinis' introduction. A fish's thermal preference, measured through laboratory studies, represents a snapshot of the thermal regulation employed by the fish and has been found to correlate with its optimal physiological performance [54]; an interruption to a fish's natural thermal regulation may reduce its physiological performance. Boltaña et al. [55] reported negative effects of a restricted thermal regime, inhibiting thermal regulation, on the early life-stage growth, survival, and cellular microstructure of Atlantic salmon. In the current study, the introduction of $G$. affinis altered the thermal preference of $C$. eos, which we hypothesize would shift the latter's physiological performance.

The observed increased movement of $21 \%$ by C. eos in this study could result in an increased mortality risk. For example, the increased energy requirements indicate a need to consume more food [20], which can increase its predation risk [21]. In addition, the increased energetic costs of movement can reduce somatic growth [22]; alternatively, that energy could have been put toward gonadal growth [56]. Trudel and Boisclair [57] found the activity costs of hybrids of northern redbelly dace and finescale dace, Phoxinus eos Cope $\mathrm{x}$ Phoxinus neogaeus Cope, ranged from 36.8 to $153.0 \mathrm{~J}$ per $12 \mathrm{~h}^{-1}$ in July and 17.0 to

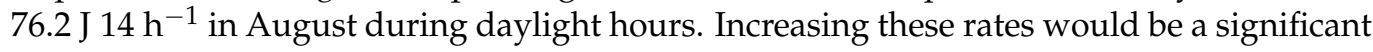
cost to C. eos and potentially cross an energetic threshold.

G. affinis is widely considered an aggressive nipper and chaser with agonistic behaviors toward other species frequently being documented $[8,9,58]$. These interactions can lead to increased inter-specific competition and the native fish being displaced from its thermally preferred habitat [38]. However, our results suggest that the effect of G. affinis agonistic interactions might be species- or condition-specific. Contrary to our hypothesis, we observed significantly more (six times as many) chases initiated by C. eos than G. affinis. The aggression by C. eos toward G. affinis led to the observed thermal displacement and increased movement. Additionally, although it was not a motivating factor in our study, our study design allowed an inference regarding wild and hatchery-reared fish interactions. It might be expected that hatchery fish would be more docile and that wild fish would be more aggressive. However, our results showed the hatchery-reared fish to be more aggressive than the wild-caught fish. The literature on the aggression of wild versus hatchery-reared fish is mixed. For example, Deverill et al. [59] found wild brown trout Salmo trutta initiated more aggressive acts than hatchery-reared S. trutta. However, Mesa [60] found that hatchery-reared coastal cutthroat trout Oncorhynchus clarki clarki were more aggressive than their wild conspecifics.

The lack of G. affinis aggression observed here may have been influenced by a variety of factors including the fish's size, prior residency, and water temperature. The C. eos were, on average, larger than the G. affinis; however, G. affinis have been shown to be aggressive toward larger species [58]. Prior residency is the hypothesis that the individual who is already a resident in a habitat has an advantage in territory contests over an intruder [61-63]. In our case, C. eos would have prior residency in a natural setting as the native species, so this study design approximates conditions in which these encounters would occur during biological invasions. The range of temperatures tested in this study are closer to the preference of $C \cdot \operatorname{eos}\left(24^{\circ} \mathrm{C}\right)$ than $G$. affinis $\left(31^{\circ} \mathrm{C}\right)$, but within the range of temperatures G. affinis and C. eos experience naturally $[27,53]$. 
Manipulation effects may also influence the results of behavioral studies and should be accounted for-especially in studies in which fish are netted, removed from water, and transferred to another tank-as these manipulations can affect fish behaviors [64-67]. We attempted to minimize and control manipulation effects by allowing a $1.5 \mathrm{~h}$ acclimation period for C. eos to establish their thermal preference. This allowed the fish to settle after being transported, time to explore the thermal preference chamber, and time to select their preferred temperature. Once G. affinis were introduced, we allowed a 15 min acclimation period to account for any short-term responses to subside.

This study focused on the adult life stage of these species; however, significant knowledge gaps remain in our understanding of how G. affinis impact earlier life stages of C. eos. Both species are omnivores [16,23,24], so competition for food resources likely occurs at all life stages. For earlier life stages, there is also likely competition for habitats- both preferred thermal habitats and vegetation that provides protection from predators. The potential for competition between G. affinis and C. eos in their early life stages is compounded by G. affinis' reproductive strategy. G. affinis is a livebearer that produces prodigious amounts of offspring [16]; these offspring may overwhelm C. eos in its early life stages in terms of competition for food and habitat availability. In addition, adult G. affinis may predate on C. eos in its early life stages.

\section{Conclusions}

In this study, we observed a native fish shifting its temperature preference in the presence of G. affinis in an experimental chamber simulating a thermally heterogeneous habitat, but aggressive behaviors were more frequently observed in the native fish toward G. affinis rather than the other direction. We hypothesize that indirect mechanisms (e.g., reduced growth via a thermal displacement and increased movement), not direct agonistic behaviors, may negatively affect C. eos in the presence of G. affinis. Conservation actions that may help conserve remaining glacial relict populations of $C$. eos include: protecting thermal refugia; promoting habitat enhancement strategies for C. eos; the hatchery stocking of C. eos into suitable habitats, with priority given to areas that do not include G. affinis; and establishing genetic refugia in hatcheries that can be used as source populations for hatchery releases. The thermal experimental chamber used in this study is a promising tool to study the thermal preference, and changes in preference and behavior, of native fish in the presence of invasive species. Additional research is needed to identify which native species are vulnerable to the direct and indirect effects of G. affinis' presence, especially given the likelihood of increasing temperatures, which would favor G. affinis. Future studies should examine temperatures outside of those included in this study, especially higher temperatures, to test the hypothesis that behaviors change at elevated temperatures. Additional research may also include further investigation into the impacts of G. affinis on native fish populations relative to the other ecological traits, especially its reproductive output, of this highly successful invasive species.

Author Contributions: Conceptualization, L.R.C. and R.M.F.; methodology, L.R.C., R.M.F. and Y.K.; software, R.M.F. and Y.K.; validation, L.R.C. and Y.K.; formal analysis, Y.K.; investigation, L.R.C., R.M.F., S.T.L. and Y.K.; resources, R.M.F.; data curation, L.R.C.; writing-original draft preparation, L.R.C., R.M.F., S.T.L. and Y.K.; writing-review and editing, L.R.C., R.M.F., S.T.L. and Y.K.; visualization, L.R.C., R.M.F., S.T.L. and Y.K.; supervision, R.M.F.; project administration, R.M.F.; funding acquisition, R.M.F. All authors have read and agreed to the published version of the manuscript.

Funding: This research was funded by Colorado Parks and Wildlife through the Species Conservation Trust Fund (Project \#911C).

Institutional Review Board Statement: The care and use of experimental animals complied with the State of Colorado's animal welfare laws, guidelines, and policies as approved by the State of Colorado Scientific Collection License \#05-AQ96.

Data Availability Statement: Data are available upon request. 
Acknowledgments: The authors would like to thank Steven Brinkman and Jordan Anderson for their assistance with building the thermal preference chamber, as well as Brittany Woodward and Jason Hanlon for watching hours of video. We appreciate Harry Crockett, Ryan Friebertshauser, and three anonymous reviewers for providing comments and improving this manuscript.

Conflicts of Interest: The authors declare no conflict of interest.

\section{References}

1. Olden, J.D.; Poff, N.L. Toward a mechanistic understanding and prediction of biotic homogenization. Am. Nat. 2003, 162, 442-460. [CrossRef] [PubMed]

2. Gallardo, B.; Clavero, M.; Sánchez, M.I.; Vilá, M. Global ecological impacts of invasive species in aquatic ecosystems. Glob. Chang. Biol. 2016, 22, 151-163. [CrossRef]

3. Vander Zanden, M.J.; Lapointe, N.W.R.; Marchetti, M.P. Non-indigenous fishes and their role in freshwater imperilment. In Conservation of Freshwater Fishes; Closs, G.P., Krkosek, M., Olden, J.D., Eds.; Cambridge University Press: Cambridge, UK, 2016; Volume 1, pp. 238-269.

4. Van Snik Gray, E.; Stauffer, J.R., Jr. Substrate choice by three species of darters (Teleostei: Percidae) in an artificial stream: Effects of a nonnative species. Copeia 2001, 2001, 254-261. [CrossRef]

5. Hasegawa, K.; Yamamoto, T.; Murakami, M.; Maekawa, K. Comparison of competitive ability between native and introduced salmonids: Evidence from pairwise contests. Ichthyol. Res. 2004, 51, 191-194. [CrossRef]

6. McMahon, T.E.; Zale, A.V.; Barrows, F.T.; Selong, J.H.; Danehy, R.J. Temperature and competition between Bull Trout and Brook Trout: A test of the elevation refuge hypothesis. Trans. Am. Fish. Soc. 2007, 136, 1313-1326. [CrossRef]

7. Courtenay, W.R., Jr.; Meffe, G.K. Small fishes in strange places: A review of introduced poeciliids. In Ecology and Evolution of Livebearing Fishes (Poeciliidae); Meffe, G.K., Snelson, F.F., Jr., Eds.; Prentice Hall: Englewood Cliffs, NJ, USA, 1989 ; pp. 319-331.

8. Lowe, S.; Browne, M.; Boudjelas, S.; De Poorter, M. 100 of the World's Worst Invasive Alien Species. A Selection from the Global Invasive Species Database. Published by the Invasive Species Specialist Group. Available online: https://rewilding.org/wpcontent/uploads/2012/04/IUCN-GISP.pdf (accessed on 15 September 2021).

9. Schumann, D.A.; Hoback, W.W.; Koupal, K.D. Complex interactions between native and invasive species: Investigating the differential displacement of two topminnows native to Nebraska. Aquat. Invasions 2015, 10, 339-346. [CrossRef]

10. Segev, O.; Mangel, M.; Blaustein, L. Deleterious effects by mosquitofish (Gambusia affinis) on the endangered fire salamander (Salamandra infraimmaculata). Anim. Conserv. 2008, 12, 29-37. [CrossRef]

11. Schulse, C.D.; Semlitsch, R.D.; Trauth, K.M. Mosquitofish dominate amphibian and invertebrate community development in experimental wetlands. J. Appl. Ecol. 2013, 50, 1244-1256. [CrossRef]

12. Peck, G.W.; Walton, W.R. Effects of mosquitofish (Gambusia affinis) and sestonic food abundance on the invertebrate community within a constructed treatment wetland. Freshw. Biol. 2008, 53, 2220-2233. [CrossRef]

13. Preston, D.L.; Hedman, H.D.; Esfahani, E.R.; Pena, E.M.; Boland, C.E.; Lunde, K.B.; Johnson, P.J.T. Responses of a wetland ecosystem to the controlled introduction of invasive fish. Freshw. Biol. 2017, 62, 767-778. [CrossRef]

14. Harmon, J.J.; Smith, G.R. Invasive fish (Gambusia affinis) as an ecological filter for macroinvertebrate colonization of experimental ponds. Freshw. Sci. 2020, 40, 151-161. [CrossRef]

15. Otto, R.G. Temperature tolerance of the mosquitofish, Gambusia affinis (Baird and Girard). J. Fish Biol. 1973, 5, 575-585. [CrossRef]

16. Pyke, G.H. A review of the biology of Gambusia affinis and G. holbrooki. Rev. Fish Biol. Fisher. 2005, 15, 339-365. [CrossRef]

17. Mills, M.D.; Rader, R.B.; Belk, M.C. Complex interactions between native and invasive fish: The simultaneous effects of multiple negative interactions. Oecologia 2004, 141, 713-721. [CrossRef]

18. Laha, M.; Mattingly, H.T. Ex Situ evaluation of impacts of invasive mosquitofish on the imperiled Barrens topminnow. Environ. Biol. Fish. 2007, 78, 1-11. [CrossRef]

19. Sutton, T.M.; Zeiber, R.A.; Fisher, B.E. Agonistic behavioral interactions between introduced western mosquitofish and native topminnows. J. Freshw. Ecol. 2013, 28, 1-16. [CrossRef]

20. Boisclair, D.; Leggett, W.C. The importance of activity in bioenergetics models applied to actively foraging fishes. Can. J. Fish. Aquat. Sci. 1989, 46, 1859-1867. [CrossRef]

21. Hulthén, K.; Chappman, B.B.; Nilsson, P.A.; Hansson, L.; Skov, C.; Brodersen, J.; Vinterstare, J.; Brönmark, C. A predation cost to bold fish in the wild. Sci. Rep. 2017, 7, 1-5. [CrossRef] [PubMed]

22. Rennie, M.D.; Collins, N.C.; Shuter, B.J.; Rajotte, J.W.; Couture, P. A comparison of methods for estimating activity costs of wild fish populations: More active fish observed to grow slower. Can. J. Fish. Aquat. Sci. 2004, 62, 767-780. [CrossRef]

23. Stasiak, R. Northern Redbelly Dace (Phoxinus eos): A Technical Conservation Assessment. [Online]. USDA Forest Service, Rocky Mountain Region. Available online: http://www.fs.fed.us/r2/projects/scp/assessments/northernredbellydace.pdf (accessed on 15 September 2021).

24. Bestgen, K.R. Distribution and notes on the biology of Phoxinus eos (Cyprinidae) in Colorado. Southwest. Nat. 1989, 34, 225-231. [CrossRef]

25. Stasiak, R.H. Phoxinus eos (Cope), northern redbelly dace. In Atlas of North American Freshwater Fishes; Lee, D.S., Gilbert, C.R., Hocutt, C.H., Jenkins, R.E., McAllister, D.E., Stauffer, J.R., Jr., Eds.; North Carolina State Museum of Natural History: Raleigh, NC, USA, 1980; p. 336. 
26. Carveth, C.J.; Widmer, A.M.; Bonar, S.A. Comparison of upper thermal tolerances of native and nonnative fish species in Arizona. T. Am. Fish. Soc. 2006, 135, 1433-1440. [CrossRef]

27. Winkler, P. Thermal preference of Gambusia affinis affinis as determined under field and laboratory conditions. Copeia 1979, 60-64. [CrossRef]

28. Brett, J.R. Energetic response of salmon to temperature. A study of some thermal relations in the physiology and freshwater ecology of sockeye salmon (Oncorhynchus nerka). Am. Zool. 1971, 11, 99-113. [CrossRef]

29. Coutant, C.C. Thermal preference: When does an asset become a liability? Environ. Biol. Fish. 1987, 18, 161-172. [CrossRef]

30. Beauchamp, D. Bioenergetic Ontogeny: Linking climate and mass-specific feeding to life-cycle growth and survival of salmon. Am. Fish. Soc. Symp. 2009, 70, 53-72.

31. Pankhurst, N.W.; Munday, P.L. Effects of climate change on fish reproduction and early life history stages. Mar. Freshw. Res. 2011, 62, 1015-1026. [CrossRef]

32. Colchen, T.; Teletchea, F.; Fontaine, P.; Pasquet, A. Temperature modifies activity, inter-individual relationships and group structure in a fish. Curr. Zool. 2017, 63, 175-183. [CrossRef] [PubMed]

33. Kessler, K.; Lampert, W. Fitness optimization of Daphnia in a trade-off between food and temperature. Oecologia 2004, 140, 381-387. [CrossRef]

34. Morris, W. Adaptation and habitat selection in the eco-evolutionary process. Proc. R. Soc. B. 2011, 278, 2401-2411. [CrossRef]

35. Brewitt, K.S.; Danner, E.M.; Moore, J.W. Hot eats and cool creeks. Hot eats and cool creeks: Juvenile Pacific salmonids use mainstem prey while in thermal refuges. Can. J. Fish. Aquat. Sci. 2017, 74, 1588-1602. [CrossRef]

36. Taniguchi, Y.; Rahel, F.J.; Novinger, D.C.; Gerow, K.G. Temperature mediation of competitive interactions among three fish species that replace each other along longitudinal stream gradients. Can. J. Fish. Aquat. Sci. 1998, 55, 1894-1901. [CrossRef]

37. Taniguchi, Y.; Nakano, S. Condition-specific competition: Implications for the altitudinal distribution of stream fishes. Ecology 2000, 81, 2027-2039. [CrossRef]

38. Yamada, T.; Koizumi, I.; Urabe, H.; Nakamura, F. Temperature-dependent swimming performance differs by species: Implications for condition-specific competition between stream salmonids. Zool. Sci. 2020, 37, 429-433. [CrossRef]

39. Carmona-Catot, G.; Magellan, G.K.; García-Berthou, E. Temperature specific competition between invasive Mosquitofish and endangered Cyprinodontid fish. PLoS ONE 2013, 8, e54734. [CrossRef] [PubMed]

40. Majerova, M.; Neilson, B.T.; Roper, B.B. Beaver dam influences on streamflow hydraulic properties and thermal regimes. Sci. Total Environ. 2020, 718, 134853. [CrossRef] [PubMed]

41. Nijman, V.; Heuts, B.A. Effect of environmental enrichment upon resource holding power in fish in prior residence situations Behav. Process. 2000, 49,77-83. [CrossRef]

42. Gilmour, K.M.; DiBattista, J.D.; Thomas, J.B. Physiological causes and consequences of social status in salmonid fish. Integr. Comp. Biol. 2005, 45, 263-273. [CrossRef]

43. Kua, Z.X.; Hamilton, I.M.; McLaughlin, A.L.; Brodnik, R.M.; Keitzer, S.C.; Gilliland, J.; Hoskins, E.A.; Ludsin, S.A. Water warming increases aggression in a tropical fish. Sci. Rep. 2020, 10, 1-13. [CrossRef]

44. Kelly, N.I.; Burness, G.; McDermid, J.L.; Wilson, C.C. Ice age fish in a warming world: Minimal variation in thermal acclimation capacity among lake trout (Salvelinus namaycush) populations. Conserv. Physiol. 2014, 2, 1-14. [CrossRef] [PubMed]

45. Myrick, C.A.; Kurtis, F.D.; Cech, J.J. An annular chamber for aquatic animal preference studies. Trans. Am. Fish. Soc. 2004, 133, 427-433. [CrossRef]

46. Caballero, C.; Castro, J.J. Effect of residence and size asymmetries upon the agonistic interactions between juvenile white-seabream (Diplodus sargus cadenati de la Paz, Bauchot and Daget, 1974). Aggress. Behav. 1999, 25, 297-303. [CrossRef]

47. Domínguez-Castanedo, O. Agonistic interactions with asymmetric body size in two adult-age groups of the annual killifish Millerichthys robustus (Miller \& Hubbs, 1974). J. Fish Biol. 2021, 2021, 1-9. [CrossRef]

48. Slivko, V.M.; Zhokhov, A.E.; Gopko, M.V.; Mikheev, V.N. Agonistic behavior of young perch Perca fluviatilis: The effects of fish size and macroparasite load. J. Ichthyol. 2021, 61, 476-481. [CrossRef]

49. Plummer, M. JAGS Version 4.3.0 User Manual [online]. Available online: http://mcmc-jags.sourceforge.net (accessed on 12 May 2019).

50. R Core Team. R: A Language and Environment for Statistical Computing. Available online: https://www.R-project.org/ (accessed on 29 September 2021).

51. Kellner, K. jagsUI: A Wrapper around 'rjags' to Streamline "JAGS" Analyses; R Package Version 1.5.2. Available online: https: / / cran.r-project.org/web/packages/jagsUI/index.html (accessed on 30 October 2021).

52. Gelman, A.; Hill, J. Data Analysis Using Regression and Multilevel/Hierarchical Models; Cambridge University Press: New York, NY, USA, 2007.

53. Stauffer, J.R., Jr.; Melisky, E.L.; Hocutt, C.H. Temperature preference of the northern redbelly dace Phoxinus eos (Cope). Arch. Hydrobiol. 1980, 90, 121-126.

54. Kellogg, R.L.; Gift, J.J. Relationships between optimum temperature for growth and preferred temperatures for the young of four species. Trans. Am. Fish. Soc. 1983, 112, 424-430. [CrossRef]

55. Boltaña, S.; Sanhueza, N.; Aguilar, A.; Gallardo-Escarate, C.; Arriagada, G.; Valdes, J.A.; Soto, D.; Quiñones, R.A. Influences of thermal environment on fish growth. Ecol. Evol. 2017, 7, 6814-6825. [CrossRef] [PubMed] 
56. Koch, F.; Wieser, W. Partitioning of energy in fish: Can reduction of swimming activity compensate for the cost of production? J. Exp. Biol. 1983, 107, 141-146. [CrossRef]

57. Trudel, M.; Boisclair, D. Estimation of fish activity costs using underwater video cameras. J. Fish Biol. 1996, 48, 40-53. [CrossRef]

58. Meffe, G.K. Predation and species replacement in American Southwestern Fishes: A case study. Southwest. Nat. 1985, 30, 173-187. [CrossRef]

59. Deverill, J.I.; Adams, C.E.; Bean, C.W. Prior residence, aggression and territory acquisition in hatchery-reared and wild brown trout. J. Fish Biol. 1999, 55, 868-875. [CrossRef]

60. Mesa, M.G. Variation in feeding, aggression, and position choice between hatchery and wild cutthroat trout in an artificial stream. Trans. Am. Fish. Soc. 1991, 120, 723-727. [CrossRef]

61. Harwood, A.J.; Griffiths, S.W.; Metcalfe, N.B.; Armstrong, J.D. The relative influence of prior residency and dominance on the early feeding behavior of juvenile Atlantic salmon. Anim. Behav. 2003, 65, 1141-1149. [CrossRef]

62. Nijman, V.; Heuts, B.A. Aggression and dominance in cichlids in resident-intruder tests: The role of environmental enrichment. Neotrop. Ichthyol. 2011, 9, 543-545. [CrossRef]

63. Kvingedal, E.; Einum, S. Prior residency advantage for Atlantic salmon in the wild: Effects of habitat quality. Behav. Ecol. Sociobiol. 2011, 65, 1295-1303. [CrossRef]

64. Conte, F.S. Stress and the welfare of cultured fish. Appl. Anim. Behav. Sci. 2004, 86, 205-223. [CrossRef]

65. Harper, C.; Wolf, J.C. Morphological effects of the stress response in fish. ILAR J. 2009, 50, 387-396. [CrossRef] [PubMed]

66. Monirian, J.; Sutphin, Z.; Myrick, C. Effects of holding temperature and handling stress on the upper thermal tolerance of threadfin shad Dorosoma petenense. J. Fish Biol. 2010, 76, 1329-1342. [CrossRef]

67. Schreck, C.B.; Olla, B.L.; Davis, M.W. Behavior responses to stress. In Fish Stress and Health in Aquaculture, Society for Experimental Biology Seminar Series 62; Iwama, G.K., Pickering, A.D., Sumpter, J.P., Schreck, C.B., Eds.; Cambridge University Press: Cambridge, UK, 1997; pp. 145-170. 